\title{
The Annual Variation in the Global Heat Balance of the Earth
}

\author{
J. S. Ellis ${ }^{1}$ AND T. H. Vonder HaAR \\ Colorado State University, Fort Collins, Colorado 80523
}

\author{
S. Levitus And A. H. OORT
}

Geophysical Fluid Dynamics Laboratory/NOAA, Princeton, New Jersey 08540

\begin{abstract}
An annual variation with a range of $31 \mathrm{~W} \mathrm{~m}^{-2}$ is found in the global net radiation balance of the earth The net radiation flux values measured from satellites and the changes in total heat content computed from independent sets of atmospheric and oceanic data show annual variations which are consistent with each other in both phase and magnitude. The net energy gain and loss by the planet within a year is stored and released within the system primarily by the oceans.
\end{abstract}

\section{INTRODUCTION}

The analyses of independent sets of satellite radiation flux, oceanic temperature, and atmospheric temperature and humidity data presented in this paper give, for the first time, estimates of the annually varying heat balance of the earth. As far as the authors know, an annual variation in the global heat balance has not been reported in the literature. However, an annual variation in the global net radiation balance was suggested by Simpson [1929]. Vonder Haar and Suomi [1971] and Raschke [1973] indicated the possibility of an annual variation in the radiation balance from limited sets of early satellite data. The annual variation in the radiation balance reported in this paper has been determined from a 29 -month composite of satellite data.

For global energy balance the net radiation flux across the upper atmospheric boundary must at all times equal the rate of change in total heat content of the combined atmosphereocean-cryosphere-land system. Energy available due to geothermal heating is extremely small in comparison with the flux of solar radiation [Sellers, 1965] and has been neglected in this study. Thus the energy balance for the atmosphere-earth system can be written as follows:

$$
F_{T A}=S_{A}+S_{0}+S_{L}+S_{L}
$$

in which

$$
F_{T A}=\int_{\text {globe }}[(1-A) I-R] d A
$$

is the net global flux of radiation at the top of the atmosphere,

$$
S_{A}=\frac{\partial}{\partial t} \int_{0}^{20 \mathrm{~km}} \int_{\text {globe }} \rho\left(C_{A} T+g Z+L_{e} q\right) d A d z
$$

is the rate of storage in the atmosphere,

$$
S_{0}=\frac{\partial}{\partial t} \int_{-27 \mathrm{~m}}^{0} \int_{\text {globe }} \rho C_{0} T d A d z
$$

is the rate of storage in the oceans, $S_{L}$ is the rate of storage in land (neglected in this study), $S_{I}$ is the rate of storage in snow and ice, and

\footnotetext{
${ }^{1}$ Now at Lawrençe Livermore Laboratory, Livermore, California 94550.

Copyright (C 1978 by the American Geophysical Union.
}

$A$ planetary albedo;

$C_{A}, C_{0}$ specific heat at constant volume for atmosphere and ocean;

$g$ acceleration due to gravity;

$I$ incoming solar flux;

$L_{e} \quad$ latent heat of evaporation;

$q$ specific humidity of air;

$R$ long-wave flux to space;

$t$ time;

$T$ temperature;

$z$ height;

$\rho$ density.

A height of $20 \mathrm{~km}$ was chosen as the 'top' of the atmosphere and a depth of $275 \mathrm{~m}$ as the lower limit of integration for the oceans because of the almost negligible contributions beyond these limits.

\section{BASIC DATA}

Data sets used in this study will be briefly described. Net radiative flux values were computed from a 29 -month set of satellite data. Some of the important characteristics of this data set are shown in Table 1 . The composited radiation values include data from wide-angle field of view sensors on board Experimental, Essa 7, Itos 1, and NOAA 1 satellites and medium field of view scanning sensors on board Nimbus 2 and 3 satellites. Ellis and Vonder Haar [1976] have discussed the spatial and temporal distribution of the data and uncertainties in the measurements. In a later part of this paper we will show that the total uncertainty in the composited global mean val-

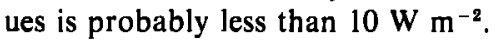

Atmospheric temperature and humidity data between the surface and 20-km height were taken from 5 years (May 1968-April 1973) of daily rawinsonde measurements at 850 meteorological stations over the globe. Figure 1 shows the distribution of these stations and illustrates the relative lack of observing stations in the southern hemisphere. As a result, less confidence can be placed in the southern hemisphere contribution to our results. The method of analysis of this data set is the same as the one used by Oort and Rasmusson [1971]. The uncertainty in the rate of atmospheric storage is less than $1 \mathrm{~W}$ $\mathrm{m}^{-2}$ for the northern hemisphere but somewhat larger for the southern hemisphere because of data void regions.

Oceanic temperature analyses were based on historical data files from the National Oceanographic Data Center, Washington, D. C., containing approximately 400,000 hydrographic soundings, 740,000 mechanical bathythermograph soundings, 
TABLE 1. Chronological List of Earth-Orbiting Satellites From Which Present Radiation Measurements Were Taken

\begin{tabular}{|c|c|c|c|c|c|c|c|c|c|}
\hline & \multicolumn{8}{|c|}{ Year } & \multirow{2}{*}{$\begin{array}{c}\text { Sample } \\
\text { Size }\end{array}$} \\
\hline & 1964 & 1965 & 1966 & 1967 & 1968 & 1969 & 1970 & 1971 & \\
\hline January & & EX $(1030)$ & & & & E7 $(1430)$ & N3 $(1130)$ & & 3 \\
\hline February & & EX (1035) & & & & E7 (1430) & & & 2 \\
\hline March & & EX (1040) & & & & E7 (1430) & & & 2 \\
\hline April & & & & & & N3 $(1130)$ & Il $(1500)$ & & 2 \\
\hline May & & & N2 (1130) & & & N3(1130) & I1 (1500) & NOl $(1500)$ & 4 \\
\hline June & & & N2(1130) & & & N3 (1130) & II (1500) & & 3 \\
\hline July & EX $(0830)$ & & N2 (1130) & & & N3 (1130) & & & 3 \\
\hline A ugust & EX $(0855)$ & & & & & N3 (1130) & & & 2 \\
\hline September & EX (0915) & & & & & & & & 1 \\
\hline October & EX (0940) & & & & E7 (1430) & N3 (1130) & & & 3 \\
\hline November & EX (1005) & & & & E7 (1430) & & & & 2 \\
\hline December & EX (1030) & & & & E7 (1430) & & & & 2 \\
\hline Annual & 6 & 3 & 3 & 0 & 3 & 9 & 4 & 1 & 29 \\
\hline
\end{tabular}

The approximate local time at which each satellite crossed the equator during daylight hours is given in parentheses. EX stands for experimental; N2, Nimbus 2; N3, Nimbus 3; E7, Essa 7; I1, Itos 1; and NO1, NOAA 1.

and 100,000 expendable bathythermograph soundings. The data were averaged by month for each $1^{\circ}$ latitude-longitude square at 11 standard levels between the surface and $250 \mathrm{~m}$. An objective analysis scheme of the iterative difference-correction type [Cressman, 1959] was applied at each standard level to produce a global analysis. A depth of $275 \mathrm{~m}$ was taken as the maximum significant depth for the penetration of the annual temperature wave. Figure 2 shows the distribution of sea surface temperature observations for the month of March. The bias toward more observations in the northern hemisphere coastal regions is true of all other months as well. Because of this bias the oceanic estimates from the southern hemisphere must be considered less reliable than the estimates from the northern hemisphere. Examination of the distribution of observations as a function of depth for all months indicates that down to $250 \mathrm{~m}$ the distributions are similar to the surface distribution, although the number of observations does decrease. The use of historical data and the general lack of observations must be considered in evaluation of the oceanic rate of storage estimates: Essentially, a sampling problem is involved. With the exception of areas around ocean weather ship stations where relatively long-term serial data exist, most of our data are scattered in time. Our ocean analysis is an attempt to describe large-scale permanent or semipermanent features of the oceanic temperature distribution. The use of observations that may have been taken during anomalous situations will be reflected in the analysis. Uncertainty in the rate of oceanic storage is about $10 \mathrm{~W} \mathrm{~m}^{-2}$, but owing to sampling deficiencies, particularly in the southern hemisphere, even this error estimate must be considered tentative. A complete description of the oceanographic data, their representativeness, and the analysis methods used can be found in the work of Levitus and Oort [1977].

The rates of heat storage in the atmosphere and ocean were computed as follows. Monthly means of the heat content were evaluated at all grid points for each month. Rate of heat storage for any particular month was then computed as the difference in heat content between the following and previous months.

The rate of storage in snow and ice was computed from the change in areal coverage of snow and ice reported by Kukla and Kukla [1974] for the period August 1968-July 1969, an average water equivalent depth of $50 \mathrm{~cm}$ for the snow and ice being assumed. The resulting values are quite small, about one half the atmospheric values, and correspondingly, their uncertainty contributes little to the uncertainty in the total rate of

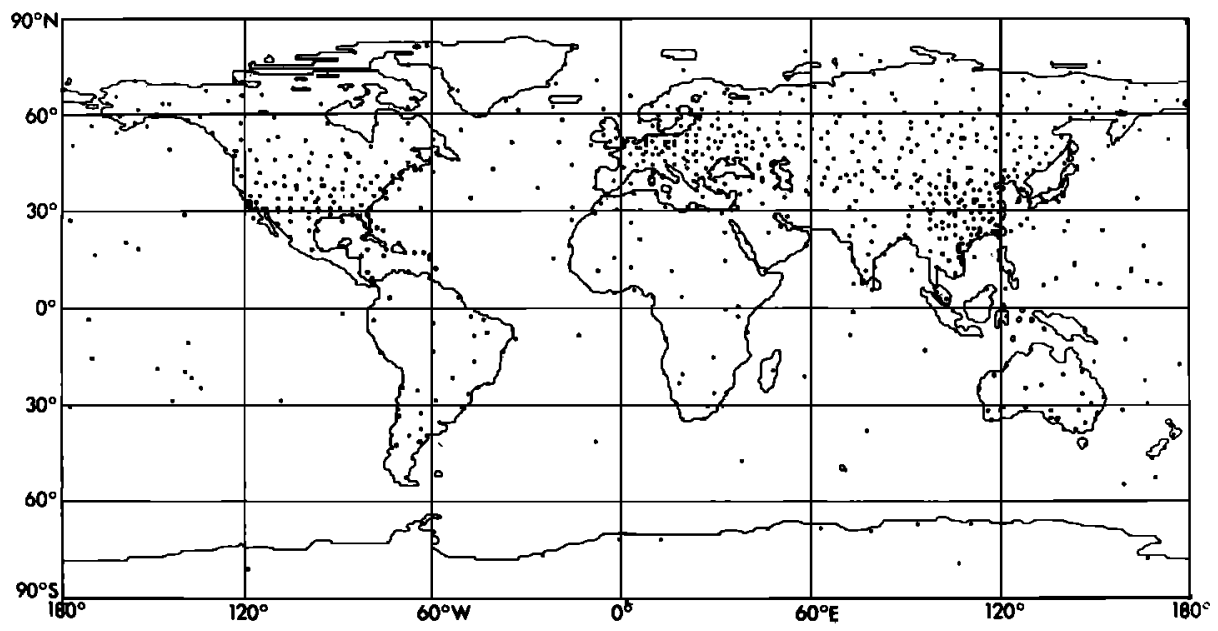

Fig. 1. Distribution of radiosonde stations. 


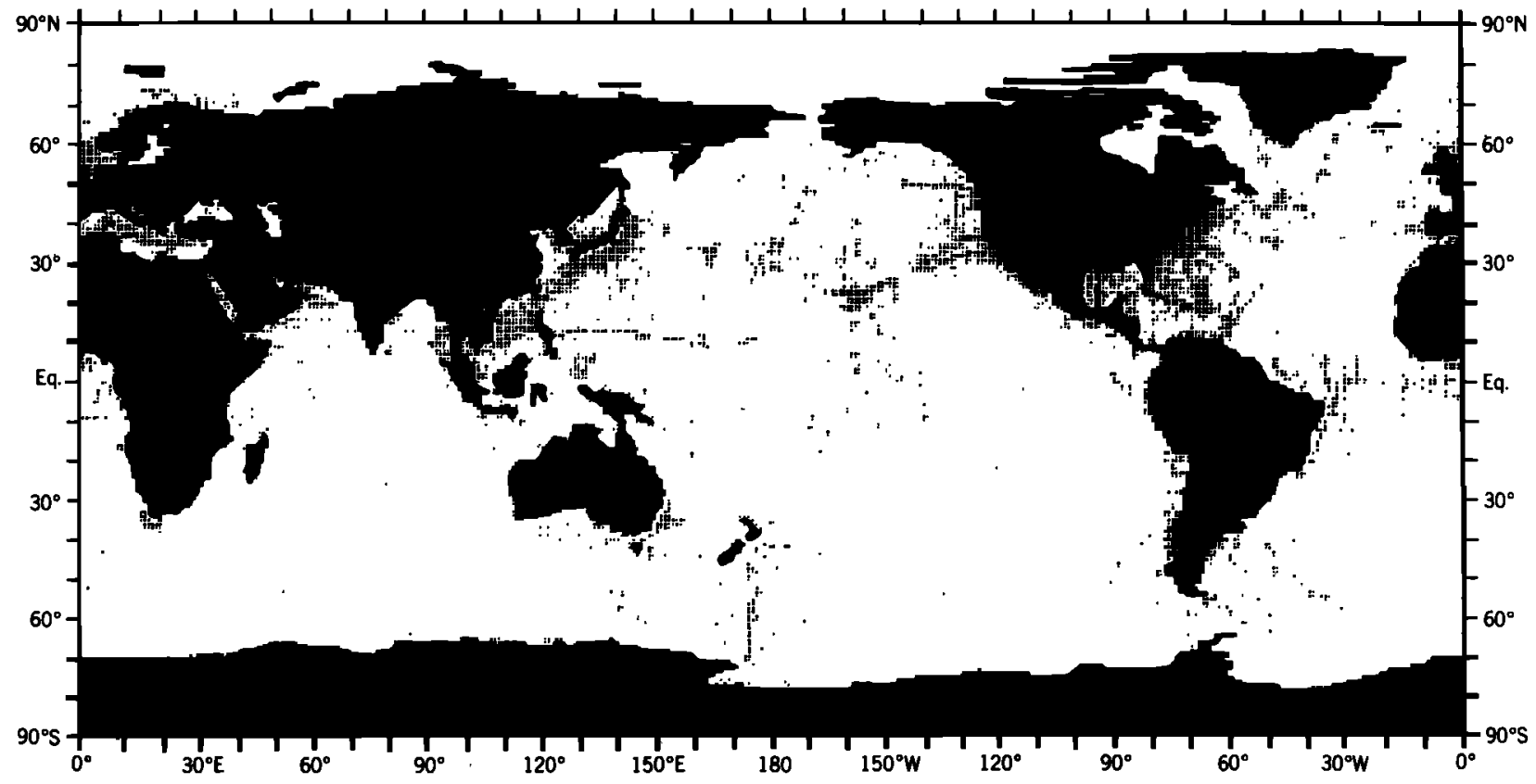

Fig. 2. Distribution of sea surface temperature observations for the month of March. A small dot indicates a $1^{\circ}$ square containıng less than 10 observations, and a large dot indicates 10 or more observations.

storage. More detailed information on the methods used in determining uncertainty in the rates of storage can be found in the work of Oart and Vonder Haar [1976].

\section{Radiation Balance Components}

The mean values of the radiation terms on the left-hand side of (1), which are based on the 29-month set of satellite data, are tabulated by month in Table 2. Shown are the global averages of reflected and long-wave flux to space at the top of the atmosphere. In addition, the computed global averages of incoming solar flux and net radiation at the top of the atmosphere are given as well as the albedo of the earth-atmosphereocean system. The incoming solar flux is computed from the known characteristics of earth-sun geometry and an assumed solar constant of $1360 \mathrm{~W} \mathrm{~m}^{-2}$ [Drummond et al., 1968].

The mean global values of planetary albedo, long-wave, and net radiation flux are also shown graphically in Figure 3. The values for the 29 individual months of our data set are indicated by crosses, while the mean annual variation is shown by a solid curve. Of the seven zero net radiation values (or

TABLE 2. Radiation Components of the Global Heat Balance

\begin{tabular}{lccccc}
\hline & $I$ & $A$ & $(1-A) I$ & $R$ & $F_{T A}$ \\
\hline January & 350.7 & 0.308 & 242.7 & 231.1 & 11.8 \\
February & 347.6 & 0.309 & 240.2 & 230.0 & 10.1 \\
March & 342.5 & 0.299 & 240.1 & 227.8 & 12.1 \\
April & 336.8 & 0.304 & 234.4 & 246.8 & -12.4 \\
May & 332.0 & 0.314 & 227.8 & 245.0 & -17.1 \\
June & 329.1 & 0.311 & 226.7 & 245.4 & -18.6 \\
July & 328.8 & 0.296 & 231.5 & 236.5 & -5.0 \\
August & 331.1 & 0.290 & 235.1 & 235.2 & -0.3 \\
September & 335.7 & 0.287 & 239.4 & 231.1 & 8.4 \\
October & 341.6 & 0.298 & 239.8 & 235.8 & 4.1 \\
November & 347.1 & 0.313 & 238.5 & 232.6 & 5.8 \\
December & 350.5 & 0.318 & 239.0 & 230.7 & 8.5 \\
Annual & 339.5 & 0.304 & 236.3 & 235.7 & 0.6 \\
\hline
\end{tabular}

All values (except $A$ ) are in units of watts per square meter. near-zero values), six are Essa 7 values. As a part of the Essa 7 data reduction method, global radiative equilibrium $\left(F_{T A}=0\right.$ ) was assumed to exist on a time scale of several days. This assumption was a necessary constraint for determining the planetary albedo. It is apparent from the distribution of values in Figure 3 that global radiative equilibrium does not generally exist even at the longer monthly time scale.

The scatter of the values about the composited net radiation profile should be a measure of the uncertainty. The plotted values suggest a value of about $10 \mathrm{~W} \mathrm{~m}^{-2}$ for the uncertainty.
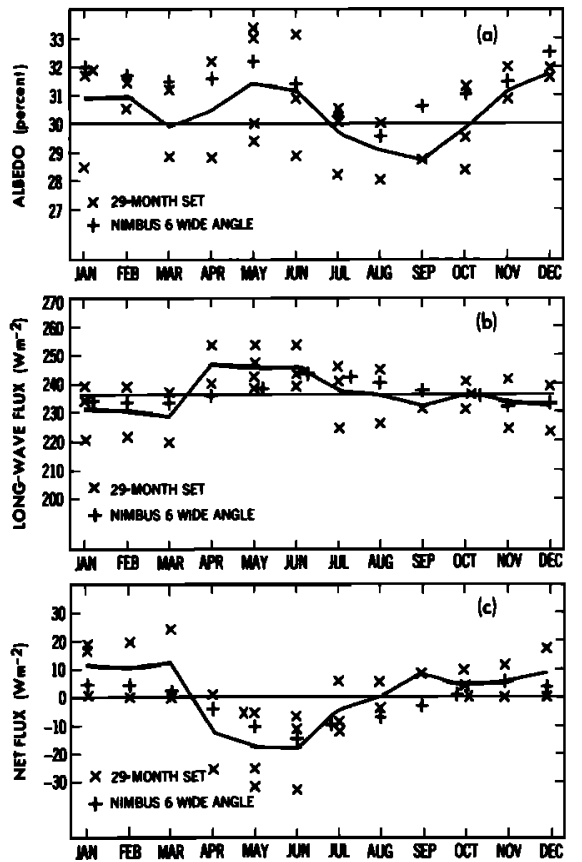

Fig. 3. Components of the global radiation balance of the earth. Shown are $(a)$ the planetary albedo, $(b)$ long-wave flux to space, and (c) net radiative flux. 
TABLE 3. Storage Components of the Global Heat Balance

\begin{tabular}{lrrrc}
\hline & $S_{0}$ & $S_{A}$ & $S_{I}^{*}$ & $S_{0}+S_{A}+S_{I}$ \\
\hline January & -6.4 & 0.9 & -0.1 & -5.6 \\
February & 1.6 & 0.7 & 0.3 & 2.6 \\
March & 18.8 & 0.7 & 0.6 & 20.1 \\
April & -5.2 & 1.6 & 0.9 & -2.7 \\
May & -25.5 & 2.2 & 0.9 & -22.4 \\
June & -9.5 & 2.6 & 1.2 & -5.7 \\
July & -1.7 & 0.6 & 0.6 & -0.5 \\
August & -6.0 & -2.1 & -0.1 & -8.2 \\
September & 5.5 & -3.1 & -0.4 & 2.0 \\
October & 5.7 & -2.8 & -0.9 & 2.0 \\
November & 9.4 & -1.4 & -2.0 & 6.0 \\
December & 13.4 & 0.0 & -1.1 & 12.3 \\
Annual & 0.0 & 0.0 & 0.0 & 0.0 \\
\hline
\end{tabular}

All values are in units of watts per square meter.

*Estimated from Kukla and Kukla [1974].

It is clear that there is an approximate $15 \mathrm{~W} \mathrm{~m}^{-2}$ amplitude wave in the seasonal net radiation profile detectable above the scatter of values.

As an independent check, monthly averaged values of the components of radiation balance from the wide-angle Earth Radiation Budget (ERB) experiment on board the Nimbus 6 satellite are also plotted in Figure 3 for the months of July 1975-June 1976. These data are not included in the composited mean profile. They are preliminary data which incorporate corrections to the calibration transfer function and earth view factor as discussed by Smith et al. [1977]. The ERB albedo values are generally larger than the composited mean values, but the phase and amplitude of the profiles are quite similar. The ERB long-wave values are an average of daytime and nighttime data, and they compare favorably with the composited profile. During the months of April and May some differences are noted which could be a manifestation of interannual variability or diurnal time-sampling bias [Ellis and Vonder Haar, 1976].

\section{Heat Storage Components}

The terrestrial components of the heat balance in the righthand side of (1), which are measured in situ, are presented in Table 3. Shown are the global rates of storage of energy in the oceans, in the atmosphere, and in the snow and ice cover for each calendar month.

To compute the typical rate of ocean storage per unit ocean area, the value of $S_{0}$ in Table 3 should be divided by 0.71 , which is the proportion of ocean to land. The storage of energy in the atmosphere and cryosphere is found to be much smaller than and approximately $90^{\circ}$ out of phase with the ocean storage and the radiation flux. The rate of storage in land is negligible, as was shown by Gabites [1950].

\section{Global Heat Balance}

A graph of the global components is shown in Figure 4. It shows that the rate of ocean storage is in close agreement with the net radiation flux except for the months of January and February. (This disagreement may be due in large part to possible errors in southern hemisphere ocean data.)

The annual variation in the earth's net radiation balance may largely be accounted for by considering the effects which the present day earth-sun geometry and the asymmetrical distribution of continents between the northern and southern hemispheres have on the net radiation balance. The orbit of the earth about the sun is such that the earth is closest to the sun in January and farthest from the sun in July. This creates an annual $11.2 \mathrm{~W} \mathrm{~m}^{-2}$ amplitude variation in the solar flux received by the planet earth.This variation is a purely external driving mechanism, since it depends only on earth-sun geometry.

When a value of $30.4 \%$ (Table 2 ) for annual mean global albedo is used, the annual $11.2 \mathrm{~W} \mathrm{~m}^{-2}$ amplitude variation of incoming solar flux translates into an approximate $7.8 \mathrm{~W} \mathrm{~m}^{-2}$ variation in absorbed solar flux at the top of the atmosphere. This value is of interest, since it gives an estimate of the variation in absorbed solar flux apparently due solely to a change in earth-sun distance.

The global albedo varies considerably from the annual mean of $30.4 \%$. This seasonal variability may be nearly described by a linear combination of an annual and semiannual wave. The minima, 29.9 in March and 28.7 in September, occur at a time when the sun is most directly over the earth's equatorial zone, which apart from a narrow band of cloudiness associated with the intertropical convergence zone has a lower albedo than the extratropics. Maxima occur when the snow- and ice-covered polar regions are receiving the greatest amount of incoming solar flux, near the solstices. An annual wave and other anomalies may be associated with the advance and retreat of sea ice and snow cover and with seasonal variability in cloud cover.

It is reasonable also to expect an annual cycle in the earth's long-wave emission to space because of the large surface temperature contrasts between land and oceans and the aşymmetric land-sea distribution between the northern and southern hemispheres. Atmospheric data show an annual cycle in the global average near-surface temperature with an amplitude of $2{ }^{\circ} \mathrm{C}$ [Van Loon, 1972]. Maximum and minimum values are found in July and January, respectively. This temperature variation may be interpreted as an amplitude variation of $7 \mathrm{~W}$ $\mathrm{m}^{-2}$ in the long-wave flux emission to space if typical atmospheric emissions are considered and all temporal variations in the intervening atmosphere are ignored [Ellis, 1977]. This effect in the long-wave flux combines with the effect in the absorbed flux to give a $15 \mathrm{~W} \mathrm{~m}^{-2}$ amplitude variation in the annual net radiation balance profile. The variation found in this suggested accounting of a cause and effect relationship is in close agreement with the variation observed in the composited profile from satellite data.

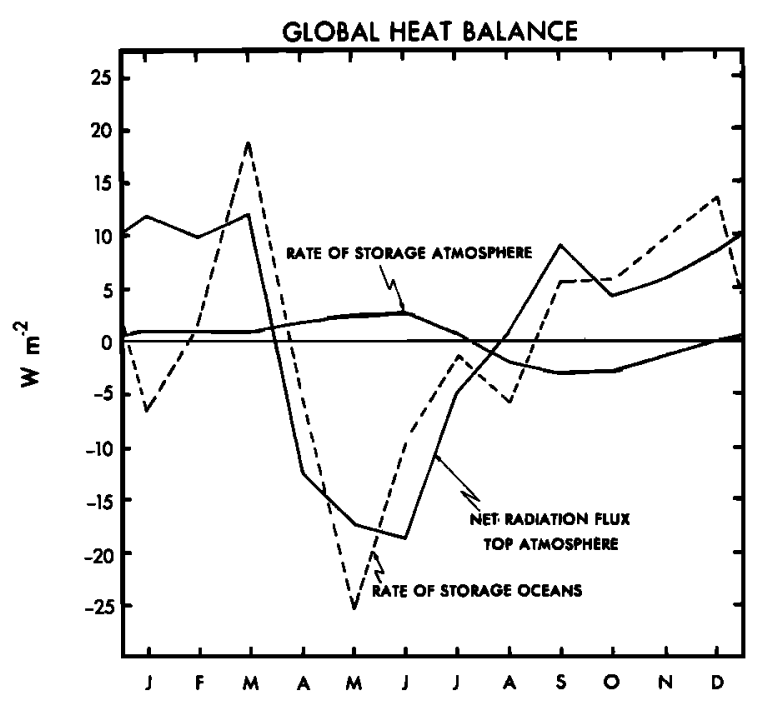

Fig. 4. Principal components of the global heat balance of the earth (in watts per square meter). 
Examination of the storage components of the global heat balance shows that the world oceans play the dominant role in the earth's response to the annual variation in incoming solar flux. This result is expected because of the exceptionally high heat capacity of water and the large portion of the planetary surface covered by oceans. The rate of heat storage in the ocean is of nearly the same amplitude and in phase with the net radiation flux. The global ocean can maintain equilibrium by an average change in its heat content between times of maximum storage and maximum release of less than $1^{\circ} \mathrm{C}$ over a 50-m-thick layer.

The atmospheric component of the global heat balance is seen to be out of phase with the net radiation flux. This is a result of the global land-sea distribution. The maximum and minimum of the atmospheric component occur during northern hemisphere summer and winter, respectively. The extremes of heating and cooling of the atmosphere over the northern hemisphere continents dominate the annual cycle.

Although the rate of storage in ice and snow is relatively small, their presence or absence may influence the global heat balance because of their effect on the earth's albedo.

There is no doubt that each of the data sets used in this study contains inaccuracies. One must also consider that the observational periods during which the data in each set were taken are different. However, the fact that the satellite radiation budget and the atmosphere-ocean heat storage data sets are independent of each other yet give results which nearly satisfy both sides of (1) suggests that the annual cycle of global heat balance presented in this paper is real. Furthermore, the independent data sets are not likely to be grossly in error. The finer details in the annual variation must be considered tentative until improved data are collected and assimilated into a composite profile.

\section{SUMmARY}

The observations discussed in this paper may be summarized as follows. There is a significant annual variation in the two major components of the global heat balance: net radiation flux and rate of ocean storage. No cause and effect relationship is established; however, the effects of the earth-sun geometry, land-sea distribution, and pole to equator albedo difference in the global net radiation balance are discussed. The combined effects are in agreement with the observed annual variation. The world oceans apparently store and release heat in phase with the annual variation in the net radiation balance. The results of this study should be tested with more accurate and more extensive data as these data sets become available. Of particular interest are possible interannual variations from the average conditions reported in this paper.

Acknowledgments. Research performed at Colorado State University was partially supported by the National Aeronautics and Space Administration grant NGR06-002-102.

\section{REFERENCES}

Cressman, G. P., An operational objective analysis scheme, Mon. Weather Rev., 87, 367-374, 1959.

Drummond, A. J., J. R. Hickey, W. J. Scholes, and E. G. Love, New value for the solar constant, Nature, 218, 259-262, 1968.

Ellis, J. S., Cloudiness, the planetary radiation budget, and climate, Ph.D. dissertation, Dep. of Atmos. Sci., Colo. State Univ., Fort Collins, 1977.

Ellis, J. S., and T. H. Vonder Haar, Zonal average earth radiation budget measurements from satellites for climate studies, Atmos. Sci. Pap. 240. 50 pp., Colo. State Univ., Fort Collins, 1976.

Gabites, J. F., Seasonal variations in the atmospheric heat balance, D. Sc. thesis, 272 pp., Mass. Inst. Technol., Cambridge, 1950.

Kukla, G. H., and H. J. Kukla, Increased surface albedo in the northern hemisphere, Science, 183, 709-714, 1974.

Levitus, S., and A. H. Oort, Global analysis of oceanographic data, Bull. Amer. Meteorol. Soc., 58, 1977.

Oort, A. H., and E. M. Rasmusson, Atmospheric circulation statistics, NOAA Prof. Pap. 5, 323 pp., U.S. Government Printing Office, Washington, D. C., 1971 .

Oort, A. H., and T. H. Vonder Haar, On the observed annual cycle in the ocean atmosphere heat balance over the northern hemisphere, $J$. Phys Oceanogr., 6, 781-800, 1976.

Raschke, E., Satellites measure the radiation budget of the earth (in German), Umschau, 73, 464-466, 1973.

Sellers, W. D., Physical Climatology, 272 pp., University of Chicago Press, Chicago, Ill., 1965.

Simpson, G. C., The distribution of terrestrial radiation, Mem. Roy. Meteorol. Soc., $I I /(23)$, 53-78, 1929.

Smith, W. L., J. Hickey, H. B. Howell, H. Jacobwitz, D. T. Hilleary, and A. J. Drummond, Nimbus-6 earth radiation budget experiment, Appl. Opt., 16, 306-318, 1977.

Van Loon, H., Temperature in the southern hemisphere, in Meteorology of the Southern Hemisphere, American Meteorology Society, Boston, Mass., 1972.

Vonder Haar, T. H., and V. E. Suomi, Measurements of the earth's radiation budget from satellites during a five-year period, I, Extended time and space means, J. Atmos. Sci., 28(3), 305-314, 1971.

(Received December 16, 1976;

revised September 8,1977 ;

accepted September 15, 1977.) 